\title{
Analysis on Decision-Making Changes of Multilevel Governments and Influencing Factors in Watershed Ecological Compensation
}

\author{
Yuansheng Wang, ${ }^{1}$ Xiaojing Wu, ${ }^{1}$ Juqin Shen, ${ }^{2}$ Chen Chi, ${ }^{3}$ and Xin Gao ${ }^{4}$ \\ ${ }^{1}$ Jiangsu Taihu Planning and Design Institute of Water Resources Co., Ltd., Suzhou 215103, China \\ ${ }^{2}$ College of Agricultural Science and Engineering, Hohai University, Nanjing 211100, China \\ ${ }^{3}$ Business School, Hohai University, Nanjing 211100, China \\ ${ }^{4}$ Antai College of Economics and Management, Shanghai Jiao Tong University, Shanghai 200030, China \\ Correspondence should be addressed to Xin Gao; gxtz1987@sjtu.edu.cn
}

Received 19 August 2021; Accepted 17 November 2021; Published 9 December 2021

Academic Editor: Feng Li

Copyright (C) 2021 Yuansheng Wang et al. This is an open access article distributed under the Creative Commons Attribution License, which permits unrestricted use, distribution, and reproduction in any medium, provided the original work is properly cited.

\begin{abstract}
Watershed ecological compensation has been widely accepted as a system to promote the cooperation of various stakeholders to solve the problem of transboundary water pollution, but the existing research does not fully consider the impact of compensation fee paid by different governments on stakeholders' decision-making. Therefore, this paper constructs a tripartite game model between upstream governments, downstream governments, and the central government by using evolutionary game theory and determines the influence of different factors on the decision-making process of each player through simulation. The results show the following: (1) the initial probability significantly affects the decision-making behavior of each player; (2) daily supervision of the central government and the reduction of the environmental protection cost can promote the implementation of watershed ecological compensation; (3) the fine to downstream governments makes the decisions of the central government and downstream governments change periodically; and (4) the increase of ecological compensation fee urges downstream governments to choose noncompensation, and compensation fee paid by the central government has a critical value.
\end{abstract}

\section{Introduction}

As the birthplace of human social civilization, watershed is one of the main sources of human available freshwater resources and an important part of natural ecosystem [1]. However, with the rapid development of social economy, the destruction of watershed ecosystem and water pollution are becoming more and more serious [2]. Due to the mobility of water resources, the pollution generated by upstream is easily transferred to downstream, resulting in the destruction of the ecological environment of the whole basin $[3,4]$. This process forms transboundary water pollution involving multiple administrative regions in the basin [5]. Therefore, how to effectively solve the problem of transboundary water pollution has become the focus of governments and scholars.

Because different regions in the basin have different needs, in order to maximize their own interests, upstream and downstream areas often have interest conflicts around the development, distribution, and utilization of water resources, resulting in the "tragedy of the commons" [6]. For example, if upstream areas protect water resources, the local government needs to pay a high cost; meanwhile downstream areas enjoy the good water; they do not pay compensation to upstream areas. This will eventually lead to the alienation of regional economic development and living standards and cause the conflicts [7]. Since transboundary water pollution usually involves many different regions, it is difficult for them to take unified action to solve this problem [8]. In recent years, many scholars have conducted in-depth research on how to solve transboundary water pollution problem and proposed many solutions [9]. Among them, payment for watershed ecosystem services (PWES), as an effective system that can promote the cooperation of upstream and downstream areas to protect watershed 
ecological environment, has attracted extensive attention all over the world $[10,11]$. Therefore, PWES provides a practical way to effectively solve the transboundary water pollution problem. PWES is the application of payments for ecosystem service (PES) in the basin, which is usually called watershed ecological compensation (WEC) in some countries. Because WEC has the advantages of promoting cooperation between upstream and downstream areas, it is widely used in major watersheds all over the world [12-14], such as Yangtze River and Yellow River in China [15-17], the Elbe River in Germany, and the Murray-Darling Basin in Australia.

For WEC, scholars have done much research on compensation identification [18, 19], standard [20-22], and mode $[23,24]$, while the key influencing factors and the decision-making changes of compensation subject and object have been attached much attention $[25,26]$. For the research of influencing factors, scholars took the compensation subject as research object and combined econometrics and conditional value method to identify them. The studies found that demographic characteristics, water consumption patterns, the close dependence between upstream and downstream areas, the awareness of improving drinking water services, and so forth were the key influencing factors [27, 28], but these studies mostly focused on the compensation subject and paid less attention to compensation object. In addition, scholars only explained the influence results but could not show the influence process of various factors. For the research of decision-making, scholars took multilevel governments (multilevel governments refer to governments with different levels in the government management hierarchy. This paper mainly refers to the central government and local governments, in which local governments mainly refer to the provincial governments along the river) as the research object and used game theory for analysis. Some scholars analyzed the decision-making behaviors by constructing the static game model between the upstream and downstream governments and found that it was difficult to construct WEC between them spontaneously $[29,30]$. However, because the static game assumes that the players are completely rational, it is difficult to realize in the real world. Therefore, some scholars have introduced evolutionary game theory $[5,31]$, but scholars mainly focused on how to promote upstream and downstream governments to establish horizontal compensation between governments at the same level, while ignoring the role of vertical compensation between the superior and subordinate governments. Moreover, the existing research has not discussed the matching relationship between horizontal compensation and vertical compensation.

Based on these research gaps, this paper constructs a tripartite evolutionary game model including upstream governments, downstream governments, and the central government in WEC, analyzes their decision-making behaviors, and identifies the key influencing factors. The innovations and contributions are as follows: (1) This paper explores the influencing factors from the perspective of multiple agents and uses simulation to show the change process of decision-making. (2) This paper also analyzes vertical compensation, horizontal compensation, and their ratio, which provides a new idea for WEC. The results can not only optimize the existing compensation mechanism but also provide reference for countries or regions that have not established WEC.

The remainder of this paper is arranged as follows. Section 2 introduces the theoretical background and research framework; Section 3 constructs the model; Section 4 carries out the simulation experiment and gets the results; Section 5 discusses the results; Section 6 obtains the conclusions and proposes suggestions.

\section{Theoretical Background and Research Framework}

2.1. Theoretical Background. Evolutionary game theory is an important branch of game theory [32]. It breaks through the hypothesis of complete rationality of players in classical game theory, integrates the evolutionary theory in biology, and uses the hypothesis of limited rationality to study the decision-making behavior of players $[33,34]$. This theory has a great influence on the study of the interaction between multiple agents. A complete research paradigm of evolutionary game theory usually includes the following parts:

(1) Determination of strategy set: in the multiagent game, different players have different alternative strategies. Then, determining the selectable strategies of each player and forming the corresponding strategy set play an important role.

(2) Construction of game matrix: game matrix is a matrix composed of payoffs of different players under different strategic combinations. The construction of the matrix can clearly reflect the specific payoffs of each player under different conditions.

(3) Establishment of replication dynamic system: replication dynamic system is a set of equations composed of a set of differential equations. It reflects the proportion of players who choose different strategies in the group and reflects the decision-making change of the whole group through the change of the proportion.

(4) Determination of evolutionary stability strategy (ESS): ESS is the combination of strategies when each player reaches a stable state. Under this strategy combination, each player can obtain its own optimal utility and will not change its own strategy. Looking for ESS is the core of evolutionary game theory $[35,36]$.

In the WEC, the needs of various stakeholders are different, and it is difficult to maintain complete rationality in the game process, so it is impossible to determine the optimal strategy in a game. Therefore, evolutionary game theory is suitable for the study of WEC [18, 37], and the application of this theory can identify the changes of decision-making behavior and the key influencing factors. 
2.2. Research Framework. The effective establishment and implementation of WEC need the full cooperation of multilevel governments, but they have different interest needs [10]. Therefore, when constructing WEC mechanism, upstream governments, downstream governments, and the central government constitute a game. The game process is shown in Figure 1.

According to Figure 1, the central government has two collective strategies: daily supervision and random inspection. When it chooses daily supervision, it hopes that the ecological, economic, and social benefits of the basin will be improved simultaneously, so as to realize the high-quality development of the basin. However, daily supervision will make the central government pay a huge cost, which will make it bear huge capital pressure. Therefore, it will choose random inspection to reduce the cost and supervise the establishment of WEC. After that, the upstream governments also have two optional strategies, namely, protecting water environment and not protecting water environment. When upstream governments choose protecting water environment, this can not only improve the ecological benefits of the whole basin but also provide high-quality water resources to downstream governments, but it will cost upstream governments. When they choose the other strategy, these costs can be used to develop the economy of the region, so as to improve the production and living standards of local residents. Finally, the optional strategy of the downstream governments is to compensate the upstream ones or not. When downstream governments pay compensation fee, this can promote upstream governments to continuously protect water environment and make downstream obtain highquality water resources continuously. In contrast, downstream governments think that using high-quality water resources is their own right and protecting water environment is the responsibility of upstream governments, so they choose not to compensate them.

Based on the game involving multilevel governments, this paper deeply analyzes their decision-making behaviors and identifies the key influencing factors, so as to provide reference for the design of appropriate WEC mechanism. The research framework is shown in Figure 2.

\section{Model}

3.1. Hypothesis. In order to fully explain the changes of decision-making behavior of different governments in the WEC and identify the key influencing factors, this paper needs to set the necessary hypotheses before building the model. The hypotheses are as follows:

(1) Each player is bounded rationality, not complete rationality. This means that it is difficult for each player to find its own optimal strategy in one game, but it can find the optimal strategy in multiple games by learning.

(2) The goal of each player is to maximize its own interests.
(3) When the upstream governments protect water environment, governments at all levels can obtain ecological benefits.

\subsection{Evolutionary Game Model}

3.2.1. Variables. The game model contains many variables, as shown in Table 1.

3.2.2. Payoff Matrices. Because different players have two optional strategies, the payoff of each player is different under different strategy combinations (Tables 2 and 3).

(1) When the central government chooses daily supervision, upstream governments choose protecting water environment and downstream governments choose compensation.

The payoff of upstream governments is

$$
V_{1}-C_{1}+H_{1}+H_{2} \text {. }
$$

The payoff of downstream governments is

$$
V_{2}-H_{1} \text {. }
$$

The payoff of the central government is

$$
V_{3}-C_{2}-H_{2} \text {. }
$$

(2) When the central government chooses daily supervision, upstream governments choose protecting water environment and downstream governments choose no compensation.

The payoff of upstream governments is

$$
V_{1}-C_{1}+H_{2} \text {. }
$$

The payoff of downstream governments is

$$
V_{2}-F_{2} \text {. }
$$

The payoff of the central government is

$$
V_{3}-C_{2}-H_{2}+F_{2} \text {. }
$$

(3) When the central government chooses daily supervision, upstream governments choose not to protect water environment and downstream governments choose compensation.

The payoff of upstream governments is

$$
H_{1}-F_{1} \text {. }
$$

The payoff of downstream governments is

$$
-H_{1} \text {. }
$$

The payoff of the central government is

$$
F_{1}-C_{2} \text {. }
$$




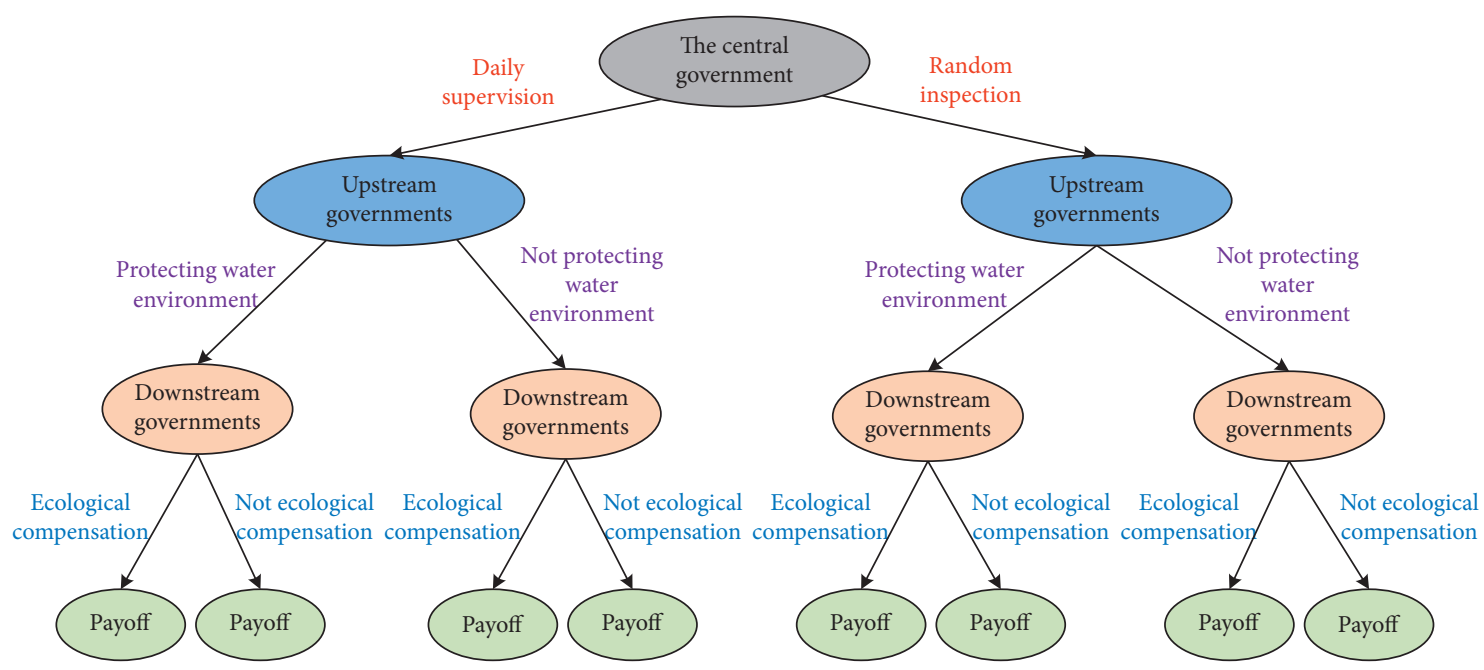

Figure 1: Game process.

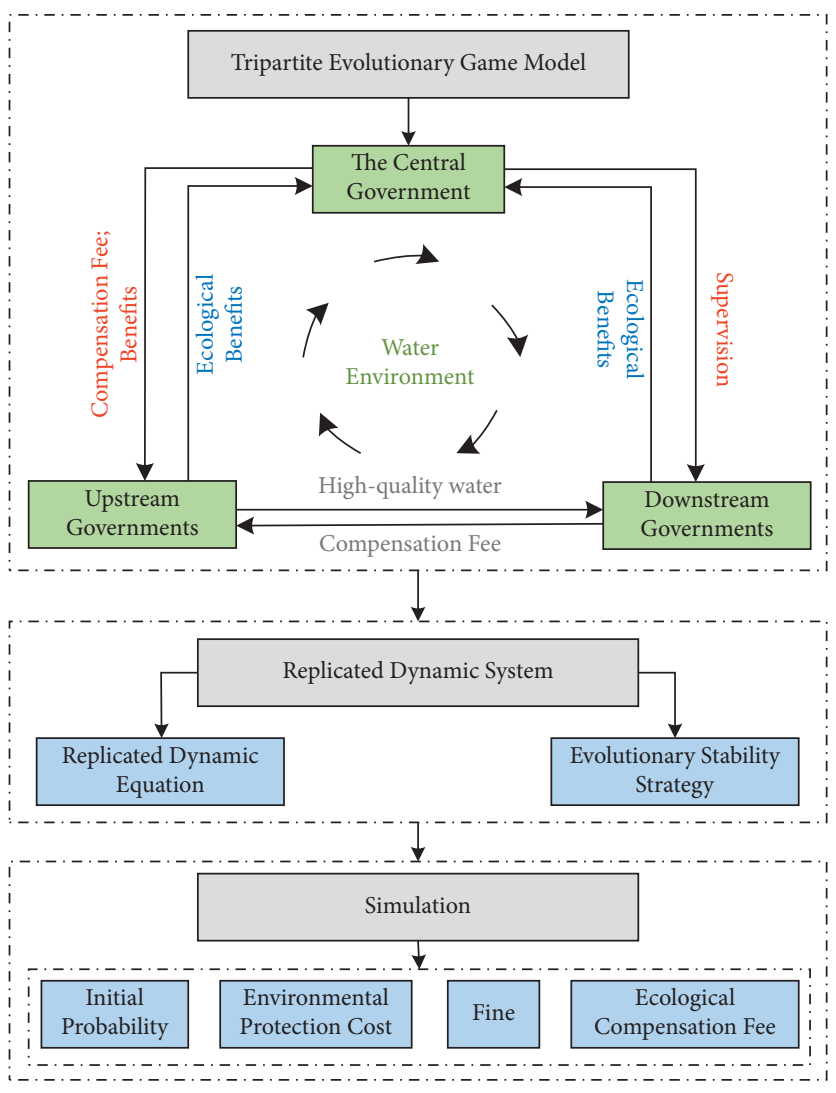

Figure 2: The research framework.

(4) When the central government chooses daily supervision, upstream governments choose not to protect water environment and downstream governments choose no compensation.

The payoff of upstream governments is
$-F_{1}$.

The payoff of downstream governments is

$-F_{2}$. 
TABLe 1: The variables in the game model.

\begin{tabular}{lc}
\hline Variable & Definition \\
\hline$C_{1}$ & Total costs of upstream governments to protect water environment \\
$C_{2}$ & Additional costs paid by the central government when choosing daily supervision \\
$F_{1}$ & The fine imposed by the central government on upstream governments when upstream governments do not protect water \\
$F_{2}$ & The fine imposed by the central government on downstream governments when downstream governments do not compensate \\
$H_{1}$ & The ecological compensation fee paid by downstream governments \\
$H_{2}$ & The ecological compensation fee paid by the central government \\
$V_{1}$ & The ecological benefits obtained by upstream governments in protecting water environment \\
$V_{2}$ & The ecological benefits obtained by downstream governments when upstream governments protect water environment \\
$V_{3}$ & The ecological benefits obtained by the central government when upstream governments protect water environment
\end{tabular}

Notes: all variables listed in Table 1 are positive.

TABLE 2: The payoff matrix of each player with daily supervision.

When the central government chooses daily supervision strategy

Downstream governments

\begin{tabular}{lccccccc} 
& \multicolumn{2}{c}{ Ecological compensation } & \multicolumn{3}{c}{ Nonecological compensation } \\
& & $\begin{array}{c}\text { Upstream } \\
\text { governments }\end{array}$ & $\begin{array}{c}\text { Downstream } \\
\text { governments }\end{array}$ & $\begin{array}{c}\text { The central } \\
\text { government }\end{array}$ & $\begin{array}{c}\text { Upstream } \\
\text { governments }\end{array}$ & $\begin{array}{c}\text { Downstream } \\
\text { governments }\end{array}$ & $\begin{array}{c}\text { The central } \\
\text { government }\end{array}$ \\
\hline & $\begin{array}{c}\text { Protecting } \\
\text { water } \\
\text { environment }\end{array}$ & $V_{1}-C_{1}+H_{1}+H_{2}$ & $V_{2}-H_{1}$ & $V_{3}-C_{2}-H_{2}$ & $V_{1}-C_{1}+H_{2}$ & $V_{2}-F_{2}$ & $V_{3}-C_{2}-H_{2}+F_{2}$ \\
$\begin{array}{l}\text { Upstream } \\
\text { governments }\end{array}$ & $\begin{array}{c}\text { Not protecting } \\
\text { water } \\
\text { environment }\end{array}$ & $H_{1}-F_{1}$ & $-H_{1}$ & $F_{1}-C_{2}$ & $-F_{1}$ & $-F_{2}$ & $F_{1}+F_{2}-C_{2}$ \\
& & & & & & &
\end{tabular}

The payoff of the central government is

$$
F_{1}+F_{2}-C_{2} \text {. }
$$

The payoff matrix with daily supervision of governments is shown in Table 2.

(5) When the central government chooses random inspection, upstream governments choose protecting water environment and downstream governments choose compensation.

The payoff of upstream governments is

$$
V_{1}+H_{1}-C_{1} \text {. }
$$

The payoff of downstream governments is

$$
V_{2}-H_{1}
$$

The payoff of the central government is

$$
V_{3} \text {. }
$$

(6) When the central government chooses random inspection, upstream governments choose protecting water environment and downstream governments choose no compensation.

The payoff of upstream governments is

$$
V_{1}-C_{1} \text {. }
$$

The payoff of downstream governments is
$V_{2}$.

The payoff of the central government is

$$
V_{3}
$$

(7) When the central government chooses random inspection, upstream governments choose not to protect water environment and downstream governments choose compensation.

The payoff of upstream governments is

$$
H_{1} \text {. }
$$

The payoff of downstream governments is

$$
-H_{1}
$$

The payoff of the central government is

$$
0 .
$$

(8) When governments choose random inspection, upstream governments choose not to protect water environment and downstream governments choose no compensation. The payoffs of them are 0 , respectively.

The payoff matrix with random inspection of the central government is shown in Table 3 . 
TABLE 3: The payoff matrix of each player with random inspection.

When the central government chooses random inspection strategy

Downstream governments

Ecological compensation

Nonecological compensation

Upstream Downstream The central Upstream Downstream The central governments governments government governments governments government

\begin{tabular}{lcccccc}
\hline $\begin{array}{l}\text { Upstream } \\
\text { governments }\end{array}$ & $\begin{array}{c}\text { Protecting water } \\
\text { environment } \\
\text { Not protecting water } \\
\text { environment }\end{array}$ & $V_{1}+H_{1}-C_{1}$ & $V_{2}-H_{1}$ & $V_{3}$ & $V_{1}-C_{1}$ & $V_{2}$ \\
\hline
\end{tabular}

3.3. Replicated Dynamic Equations. According to hypotheses, each player maximizes its own interests through learning in multiple games. Therefore, this paper uses $x, y$, and $z(x, y$, and $z \in \in[0,1])$ to represent the initial cooperation probability of upstream governments, downstream governments, and the central government choosing the strategies of protecting water environment, ecological compensation, and daily supervision, respectively.

In addition, it is assumed that $\pi_{m n}$ represents the expected payoffs of each player choosing different strategies, and $\overline{\pi_{m}}$ refers to the average payoffs of each player. $m$ represents each player, where $m=1,2$, and 3 denote upstream governments, downstream governments, and the central government, respectively; $n$ refers to the different strategies for each player, where $n=1$ and 2 denote the first strategy and the second strategy, respectively. The description of each symbol is listed in Table 4.

According to the above analysis of the payoff matrices, we can get the payoff of each player under different strategies, as shown below.

For upstream governments, the payoffs are

$$
\begin{aligned}
\pi_{11}= & y \times z \times\left(V_{1}-C_{1}+H_{1}+H_{2}\right)+y \times(1-z) \times\left(V_{1}-C_{1}+H_{2}\right) \\
& +y \times(1-z) \times\left(V_{1}+H_{1}-C_{1}\right)+(1-y) \times(1-z) \times\left(V_{1}-C_{1}\right), \\
\pi_{12}= & y \times z \times\left(H_{1}-F_{1}\right)+y \times(1-z) \times\left(-F_{1}\right)+y \times(1-z) \times H_{1}, \\
\overline{\pi_{1}}= & x \times \pi_{11}+(1-x) \times \pi_{12} .
\end{aligned}
$$

Based on $\pi_{11}, \pi_{12}$, and $\overline{\pi_{1}}$, the replicated dynamic equation of upstream governments is as follows:

$$
\begin{aligned}
F_{1}(x) & =\frac{\mathrm{d} x}{\mathrm{~d} t} \\
& =-x \times(x-1) \times\left(V_{1}-C_{1}+F_{1} \times z+H_{2} \times z\right) .
\end{aligned}
$$

For downstream governments, the payoffs are

$$
\begin{aligned}
\pi_{21}= & x \times z \times\left(V_{2}-H_{1}\right)+(1-x) \times z \times\left(-H_{1}\right)+x \times(1-z) \\
& \times\left(V_{2}-H_{1}\right)+(1-x) \times(1-z) \times\left(-H_{1}\right), \\
\pi_{22}= & x \times z \times\left(V_{2}-F_{2}\right)+(1-x) \times z \times\left(-F_{2}\right)+x \times(1-z) \times V_{2}, \\
\overline{\pi_{2}}= & y \times \pi_{21}+(1-y) \times \pi_{22} .
\end{aligned}
$$


TABle 4: The description of different symbols.

\begin{tabular}{lc}
\hline Symbol & Description \\
\hline$x$ & The probabilities that upstream governments choose to protect water environment \\
$1-x$ & The probabilities that upstream governments choose not to protect water environment \\
$y$ & The probabilities that downstream governments choose ecological compensation \\
$1-y$ & The probabilities that downstream governments choose nonecological compensation \\
$z$ & The probabilities that the central government chooses daily supervision \\
$1-z$ & The probabilities that the central government chooses random inspection \\
$\pi_{11}$ & The expected payoffs when upstream governments choose to protect water environment \\
$\pi_{12}$ & The expected payoffs when upstream governments choose not to protect water environment \\
$\pi_{21}$ & The expected payoffs when downstream governments choose ecological compensation \\
$\pi_{22}$ & The expected payoffs when downstream governments choose nonecological compensation \\
$\pi_{31}$ & The expected payoffs when the central government chooses daily supervision \\
$\frac{\pi_{32}}{\pi_{1}}$ & The expected payoffs when the central government chooses random inspection \\
$\frac{\pi_{2}}{\pi_{3}}$ & The average payoffs of upstream governments \\
\hline
\end{tabular}

Similarly, based on $\pi_{21}, \pi_{22}$, and $\overline{\pi_{2}}$, the replicated dynamic equation of downstream governments is as follows:

For the central government, the payoffs are

$$
\begin{aligned}
F_{2}(y) & =\frac{\mathrm{d} y}{\mathrm{~d} t} \\
& =y \times(y-1) \times\left(H_{1}-F_{2} \times z\right) .
\end{aligned}
$$

$$
\begin{aligned}
\pi_{31}= & x \times y \times\left(V_{3}-C_{2}-H_{2}\right)+(1-x) \times y \times\left(F_{1}-C_{2}\right)+x \times(1-y) \\
& \times\left(V_{3}-C_{2}-H_{2}+F_{2}\right)+(1-x) \times(1-y) \times\left(F_{1}+F_{2}-C_{2}\right), \\
\pi_{32}= & x \times y \times H_{2}+(1-x) \times z \times 0+x \times(1-y) \times H_{2}+(1-x) \times(1-y) \times 0, \\
\overline{\pi_{3}}= & z \times \pi_{31}+(1-z) \times \pi_{32} .
\end{aligned}
$$

Similarly, based on $\pi_{31}, \pi_{32}$, and $\overline{\pi_{3}}$, the replicated dynamic equation of the central government is as follows:

$$
\begin{aligned}
F_{3}(z)= & \frac{\mathrm{d} z}{\mathrm{~d} t} \\
= & z \times(z-1) \\
& \times\left(C_{2}-F_{1}-F_{2}+F_{1} \times x+F_{2} \times y+H_{2} \times x\right) .
\end{aligned}
$$

The replication dynamic system can be obtained by simultaneous equations (23), (25), and (27), as shown in the following equation:

$$
\left\{\begin{array}{l}
F_{1}(x)=\frac{\mathrm{d} x}{\mathrm{~d} t}=-x \times(x-1) \times\left(V_{1}-C_{1}+F_{1} \times z+H_{2} \times z\right), \\
F_{2}(y)=\frac{\mathrm{d} y}{\mathrm{~d} t}=y \times(y-1) \times\left(H_{1}-F_{2} \times z\right), \\
F_{3}(z)=\frac{\mathrm{d} z}{\mathrm{~d} t}=z \times(z-1) \times\left(C_{2}-F_{1}-F_{2}+F_{1} \times x+F_{2} \times y+H_{2} \times x\right) .
\end{array}\right.
$$


3.4. Evolutionary Stability Strategies. Because each player needs to play games for many times in order to achieve ESS, the initial probabilities change with time; that is, $x, y$, and $z$ are functions of time, so they are represented by $x(t), y(t)$, and $z(t)$. In order to obtain ESS of the replicated dynamic system, we make the differential equation (28) equal to 0 , respectively. Because $x(t), y(t)$, and $z(t) \in[0,1]$, the space for the solution of the replication dynamic system is a cube with side length of 1 . By solving the above differential equations, nine equilibrium points $\left(E_{1}(0,0,0), E_{2}(1,0,0)\right.$, $E_{3}(0,1,0), E_{4}(0,0,1), E_{5}(1,1,0), E_{6}(1,0,1), E_{7}(0,1,1)$, $E_{8}(1,1,1)$, and $\left.E_{9}\left(x^{*}, y^{*}\right)\right)$ can be obtained. $E_{9}\left(x^{*}, y^{*}\right)$ can be obtained by solving

$$
\left\{\begin{array}{l}
V_{1}-C_{1}+F_{1} \times z+H_{2} \times z=0, \\
H_{1}-F_{2} \times z=0, \\
C_{2}-F_{1}-F_{2}+F_{1} \times x+F_{2} \times y+H_{2} \times x=0 .
\end{array}\right.
$$

Although nine equilibrium points are obtained in this paper, it is uncertain whether they are ESS. Since ESS must be a pure strategy Nash equilibrium, $E_{9}$ must not be ESS, because $E_{9}$ represents a mixed strategy equilibrium. Then, we only need to judge whether the other eight points are ESS. According to Lyapunov's System Stability Theory $[38,39]$, the eigenvalues of the coefficient matrix of dynamic system can help to judge the stability of the system. When all eigenvalues are negative, the system reaches a stable state; when the eigenvalue is nonnegative, the system is in an unstable state. Therefore, firstly, this paper calculates the Jacobian matrix of the replicated dynamic system; secondly, the coordinates from $E_{1}$ to $E_{8}$ are substituted into the Jacobian matrix to obtain the corresponding eigenvalues. Finally, ESS is determined according to Lyapunov's stability theory. The Jacobian matrix with each equilibrium point can be obtained $\left(J_{1}\right.$ to $\left.J_{8}\right)$, as shown in the Appendix.

According to $J_{1}$ to $J_{8}, a_{22}$ of $J_{3}$ and $J_{5}$, and $a_{33}$ of $J_{8}$ are positive $\left(a_{l r}\right.$ refers to the eigenvalue shown in the $l$ th row and the $r$ th column of the matrix), so $E_{3}, E_{5}$, and $E_{8}$ are not ESS. Other equilibrium points cannot directly judge whether they are ESS but need to introduce constraints for further judgment. In contrast, only $E_{6}$ is most in line with the actual situation, because the WEC fee is mainly paid by the central government, and most of the downstream governments do not actively participate in the WEC. Therefore, this paper takes $E_{6}$ as the object for in-depth research. In order to make the system reach this stable state, the constraints (equation (30)) are added.

$$
\left\{\begin{array}{l}
C_{1}-H_{2}-V_{1}<0 \\
F_{2}-H_{1}<0 \\
C_{2}-F_{2}+H_{2}<0
\end{array}\right.
$$

\section{Results of Simulation}

According to the above analysis, the final stability of replication dynamic system is $E_{6}(1,0,1)$. Under equation (30), this paper uses numerical simulation technology to study decision-making of each player and the influencing factors. The initial value of each parameter is shown in Table 5.

4.1. Initial Probabilities. Since the initial probability of each player is the function of time, in order to analyze its impact on the decision-making process of each player, this paper divides the initial probability into high probability group and low probability group for comparative analysis. The results are shown in Figure 3.

In Figure 3, we can find that, whether in the high probability group or in the low probability group, the system is finally stable at $E_{6}(1,0,1)$; that is, upstream governments choose to protect water environment, downstream governments choose not to carry out ecological compensation, and the central government chooses daily supervision. In addition, it can be observed that the time for upstream governments and downstream governments to reach a stable state is shorter, while the time for the central government to reach a stable state is longer. In the high probability group, the initial probability of the central government has experienced a change process of first decreasing and then increasing, which indicates that the central government initially tends to choose random inspection and then turns to daily supervision.

4.2. Environmental Protection Cost. In order to reflect the influence of environmental production cost $\left(C_{1}\right)$ on each player, this section regards it as a variable and takes values of 1,3 , and 5 respectively, while other parameters are constants (as shown in Table 6). Under this setting, this paper sets both high probability group and low probability group to simulate the system, and the results are shown in Figure 4.

According to Figure 4, it can be found that the environmental protection cost has an impact on upstream governments and the central government in the low probability group (the initial probability is 0.4 ) but has little impact on downstream governments. In Figures 4(a) and $4(\mathrm{c})$, the impact of environmental protection cost on upstream governments and the central government is opposite. For upstream governments, the increase of environmental protection cost will prolong the time to reach a stable state. For the central government, the increase of environmental protection cost shortens the time to reach a stable state in the low probability group.

4.3. Fine. In order to illustrate the impact of fine, this paper takes fine $\left(F_{1}\right.$ and $\left.F_{2}\right)$ as variables, respectively, with values of 5,7 , and 9 , and sets other parameters as constants (as shown in Table 7). On this basis, this paper still carries out system simulation for high initial probability group and low initial probability group, and the results are shown in Figure 5.

According to Figure 5(a), the fine on upstream governments $\left(F_{1}\right)$ has a certain effect on themselves. Whether the initial probability is high or low, when the fine increases, the time for upstream governments to reach stable state 1 is shortened. In Figure 5(c), $F_{1}$ only affects the decision- 
TABLE 5: The initial values of parameters.

\begin{tabular}{lccccccccc}
\hline Parameter & $C_{1}$ & $C_{2}$ & $F_{1}$ & $F_{2}$ & $H_{1}$ & $H_{2}$ & $V_{1}$ & $V_{2}$ & $V_{3}$ \\
\hline Value & 3 & 2 & 7 & 7 & 8 & 4 & 7 & 10 & 13 \\
\hline
\end{tabular}

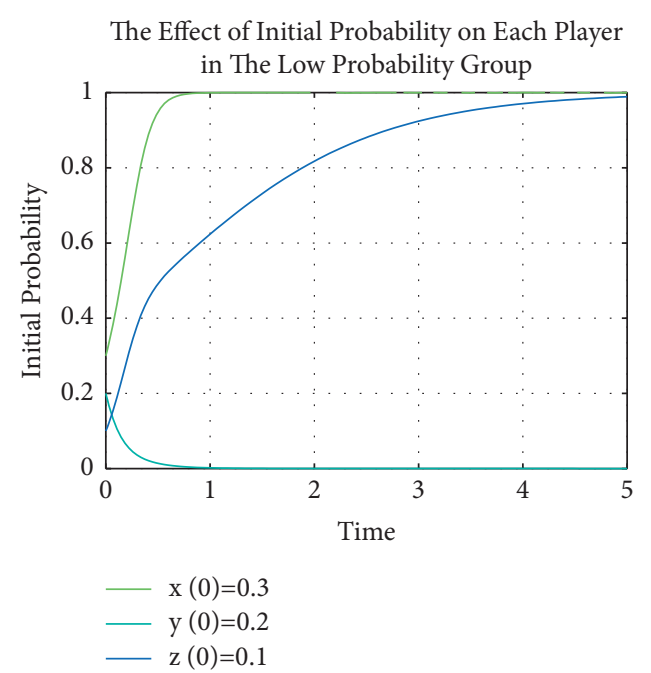

(a)

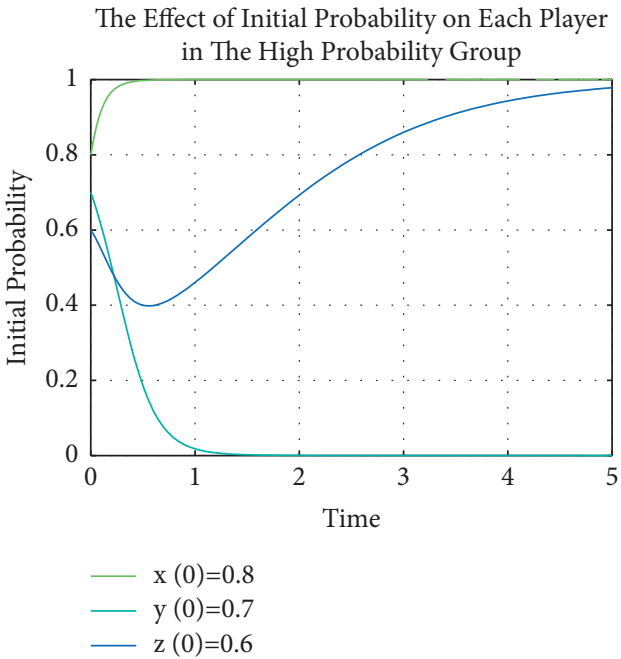

(b)

Figure 3: The effect of initial probability on each player in two groups. (a) The effect of initial probability on each player in the low probability group. (b) The effect of initial probability on each player in the high probability group.

TABLE 6: The values of parameters in the simulation of environmental protection cost $\left(C_{1}\right)$.

\begin{tabular}{lcccccccc}
\hline Parameter & $C_{2}$ & $F_{1}$ & $F_{2}$ & $H_{1}$ & $H_{2}$ & $V_{1}$ & $V_{2}$ & $V_{3}$ \\
\hline Value & 2 & 7 & 7 & 8 & 4 & 7 & 10 & 13 \\
\hline
\end{tabular}

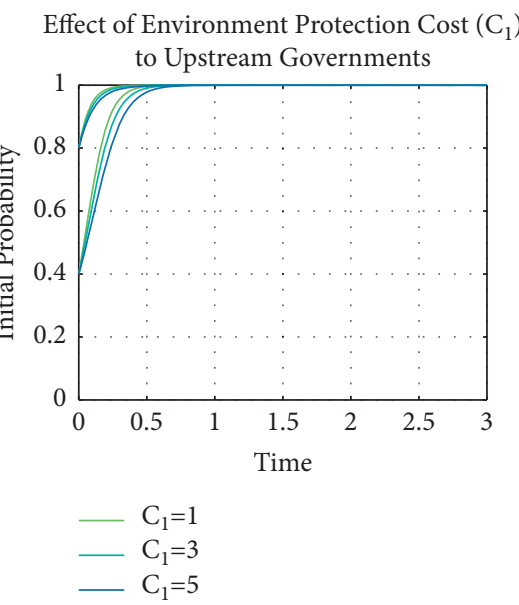

(a)

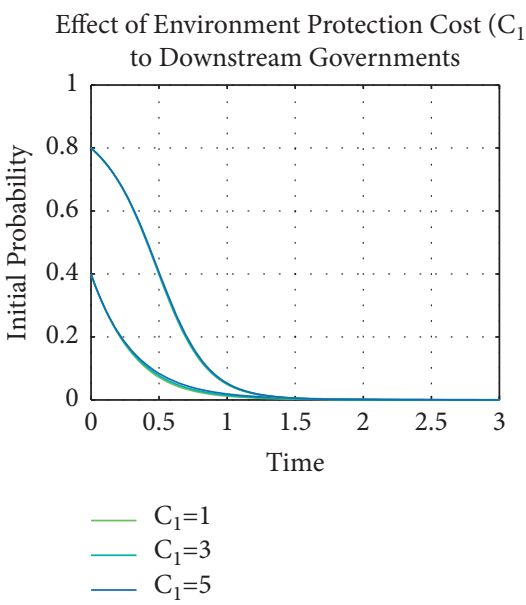

(b)

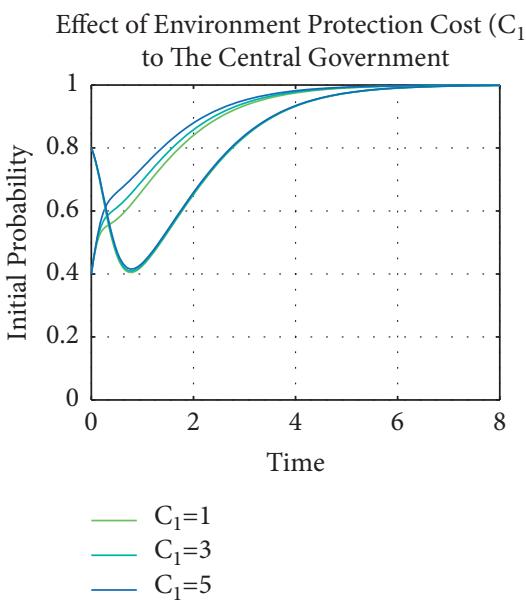

(c)

FIgURE 4: The effect of environmental protection cost $\left(C_{1}\right)$ on each player. (a) Effect of environment protection cost $\left(C_{1}\right)$ on upstream governments. (b) Effect of environment protection cost $\left(C_{1}\right)$ on downstream governments. (c) Effect of environment protection cost $\left(C_{1}\right)$ on the central government.

making of the central government in the low initial probability group; that is, when the fine increases, the time for the central government to reach stable state 1 is shortened to a certain extent. In contrast, $F_{1}$ has almost no impact on downstream governments. Similarly, according to Figures $5(\mathrm{~d})-5(\mathrm{f}), \quad F_{2}$ has little impact on upstream 
TABLE 7: The values of parameters in the simulation of fine $\left(F_{1}\right.$ and $\left.F_{2}\right)$.

\begin{tabular}{lccccccc}
\hline Parameter & $C_{1}$ & $C_{2}$ & $H_{1}$ & $H_{2}$ & $V_{1}$ & $V_{2}$ & $V_{3}$ \\
\hline Value & 3 & 2 & 8 & 4 & 7 & 10 & 13 \\
\hline
\end{tabular}

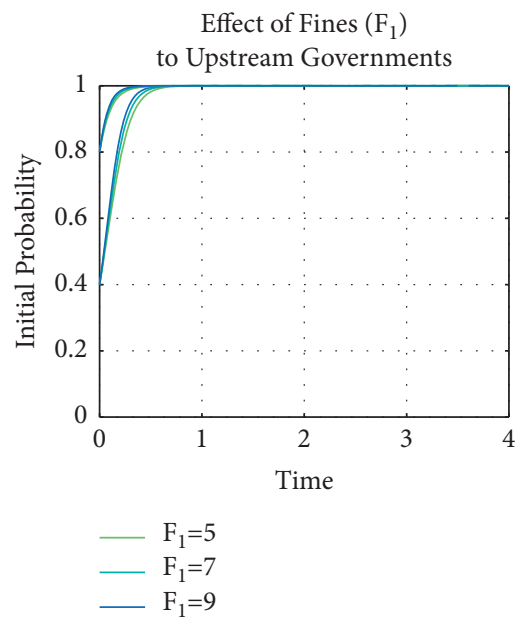

(a)

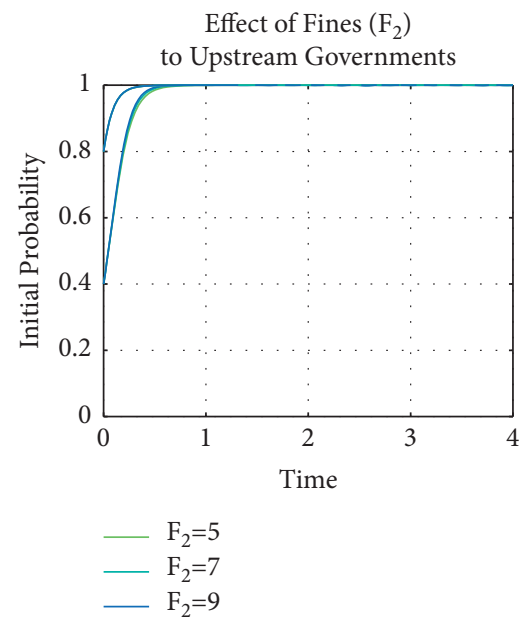

(d)

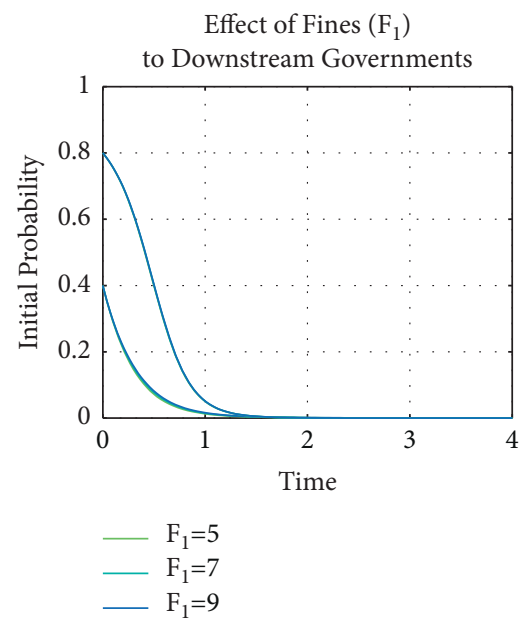

(b)

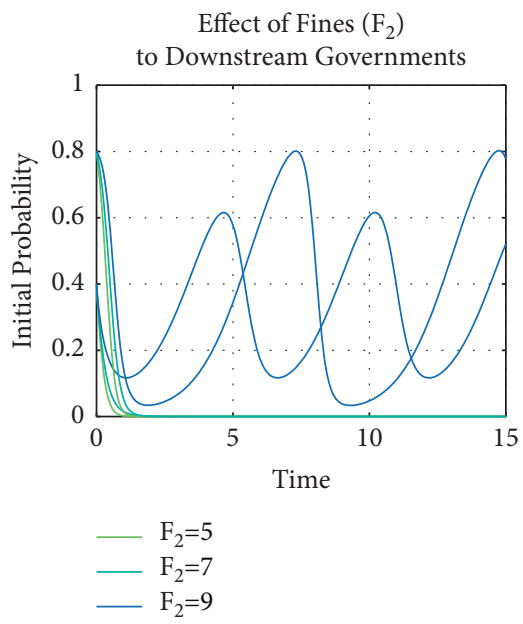

(e)

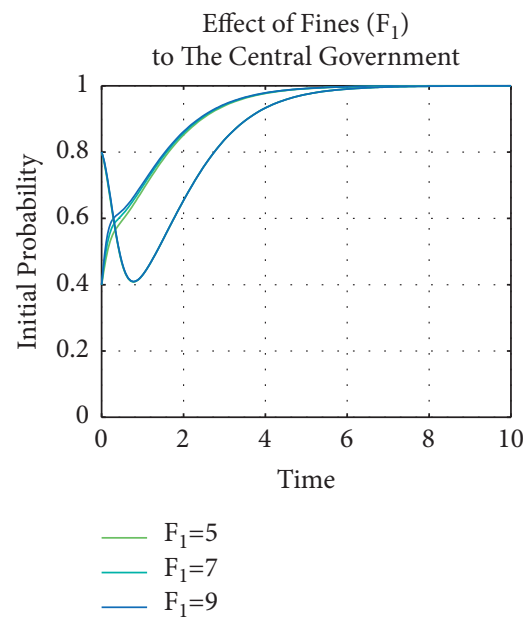

(c)

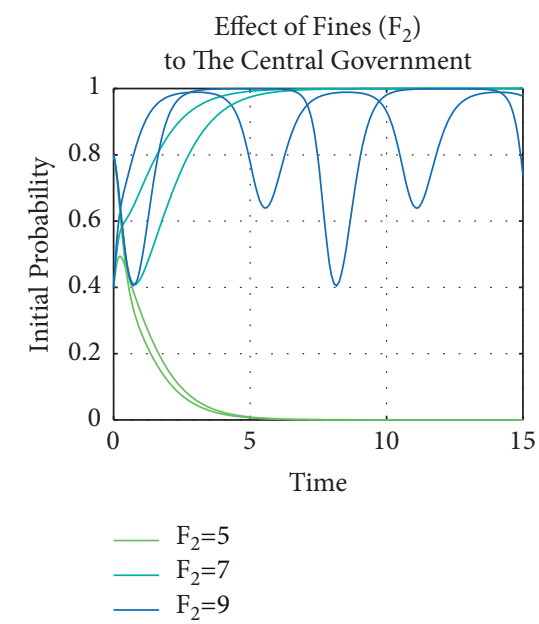

(f)

Figure 5: The effect of fines $\left(F_{1}\right.$ and $\left.F_{2}\right)$ on each player. (a) Effect of fines $\left(F_{1}\right)$ on upstream governments. (b) Effect of fines $\left(F_{1}\right)$ on downstream governments. (c) Effect of fines $\left(F_{1}\right)$ on the central government. (d) Effect of fines $\left(F_{2}\right)$ on upstream governments. (e) Effect of fines $\left(F_{2}\right)$ on downstream governments. (f) Effect of fines $\left(F_{2}\right)$ on the central government.

governments and has a great impact on downstream governments and the central government. When $F_{2}$ changes from 5 to 7 , the time for downstream governments to reach stable state 0 increases. When $F_{2}$ equals 9 , the decisionmaking of downstream governments fluctuates periodically and finds it difficult to reach a stable state. In Figure 5(f), when $F_{2}$ changes from 5 to 7 , the central government changes from state 0 to state 1 . When $F_{2}$ increases to 9 , the decision-making of the central government also shows periodic changes.
4.4. Ecological Compensation Paid by Downstream Governments. In this section, ecological compensation paid by downstream governments is regarded as a variable and taken as 6,8 , and 10 , respectively, while other parameters are taken as constants (as shown in Table 8). In addition, the system is simulated in high initial probability and low initial probability groups, respectively, and the results are shown in Figure 6.

As can be seen from Figure 6(a), the ecological compensation paid by downstream governments $\left(H_{1}\right)$ has little 
TABLE 8: The values of parameters in the simulation of ecological compensation paid by downstream governments $\left(H_{1}\right)$.

\begin{tabular}{lcccccccc}
\hline Parameter & $C_{1}$ & $C_{2}$ & $F_{1}$ & $F_{2}$ & $H_{2}$ & $V_{1}$ & $V_{2}$ & $V_{3}$ \\
\hline Value & 3 & 2 & 7 & 7 & 4 & 7 & 10 & 13 \\
\hline
\end{tabular}

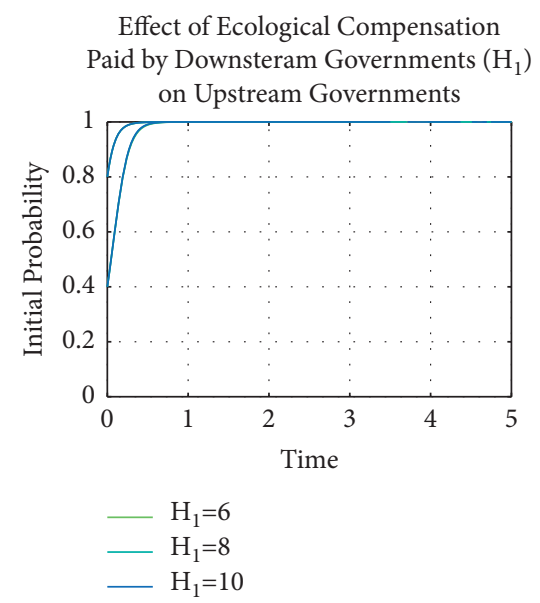

(a)

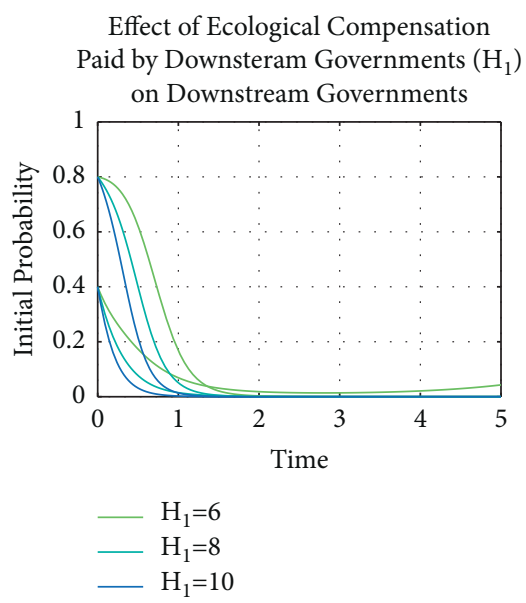

(b)

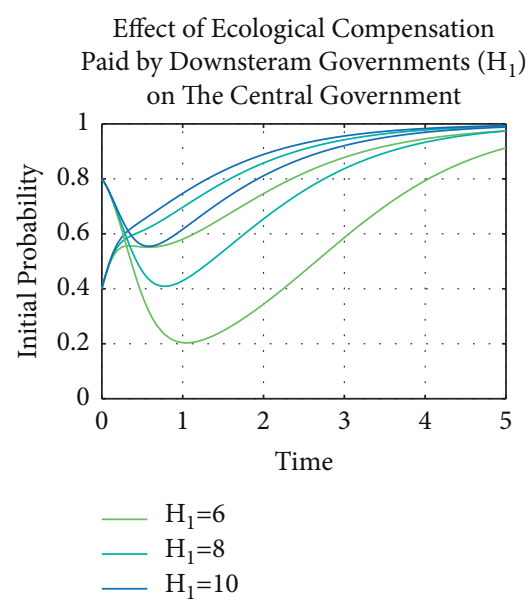

(c)

Figure 6: The effect of ecological compensation paid by downstream governments $\left(H_{1}\right)$ on each player. (a) Effect of ecological compensation paid by downstream governments $\left(H_{1}\right)$ on upstream governments. (b) Effect of ecological compensation paid by downstream governments $\left(H_{1}\right)$ on downstream governments. (c) Effect of ecological compensation paid by downstream governments $\left(H_{1}\right)$ on the central government.

impact on upstream governments. In contrast, in Figures 6(b) and 6(c), when ecological compensation paid by downstream governments increases, the speed of downstream governments and the central government reaching a stable state is significantly shortened. At this time, downstream governments will choose no compensation, while the central government will choose daily supervision.

\subsection{Ecological Compensation Paid by the Central Government.} In this section, ecological compensation paid by the central government $\left(\mathrm{H}_{2}\right)$ is regarded as a variable and taken as 2,4 , and 6 respectively, while other parameters are taken as constants (as shown in Table 9). In addition, the system is simulated in high initial probability and low initial probability groups, respectively, and the results are shown in Figure 7.

From Figure 7, ecological compensation paid by the central government has little impact on upstream governments but has a greater impact on downstream governments and the central government. In Figure 7(b), when $\mathrm{H}_{2}$ increases, the time for downstream governments to reach stable state 0 is shortened. In Figure 7(c), when $\mathrm{H}_{2}$ changes from 2 to 4 , the time for the central government to reach stable state 1 is extended. However, when $\mathrm{H}_{2}$ increases to 6 , the stable state of the central government changes from state 1 to state 0 and stabilizes at state 0 . Because the stable state of the central government has changed greatly, this paper further simulates $\mathrm{H}_{2}$, taking values from 4 to 5.4 , and the step value is 0.2 . In Figure $7(\mathrm{~d})$, when $\mathrm{H}_{2}$ is equal to 5 , the decision-making curve of the central government becomes a
TABLe 9: The values of parameters in the simulation of the ecological compensation paid by the central government $\left(\mathrm{H}_{2}\right)$.

\begin{tabular}{lcccccccc}
\hline Parameter & $C_{1}$ & $C_{2}$ & $F_{1}$ & $F_{2}$ & $H_{1}$ & $V_{1}$ & $V_{2}$ & $V_{3}$ \\
\hline Value & 3 & 2 & 7 & 7 & 4 & 7 & 10 & 13 \\
\hline
\end{tabular}

horizontal straight line, which shows that 5 is the critical value of the change of the central government's strategy.

\section{Discussion}

5.1. Initial Probabilities. From Section 3.4, it can be seen that the initial probability is the key factor for determining ESS. Therefore, the simulation of the initial probability will help to understand the sensitivity of each player's decision. According to the results in Section 4.1, in different initial probability groups, the final stable state of each player is the same; that is, the upstream governments choose to protect water environment, the downstream governments choose not to compensate, and the central government chooses daily supervision. However, there are some differences in the trend of each player reaching a stable state. For upstream governments, the time to reach a stable state in the high probability group is significantly shorter than that in the low probability group. For downstream governments, the time to reach the steady state in the low probability group is shorter than that in the high probability group. For the central government, the times to reach a stable state are close in different groups, but, in the high probability group, the curve shows a downward trend first and then an upward 


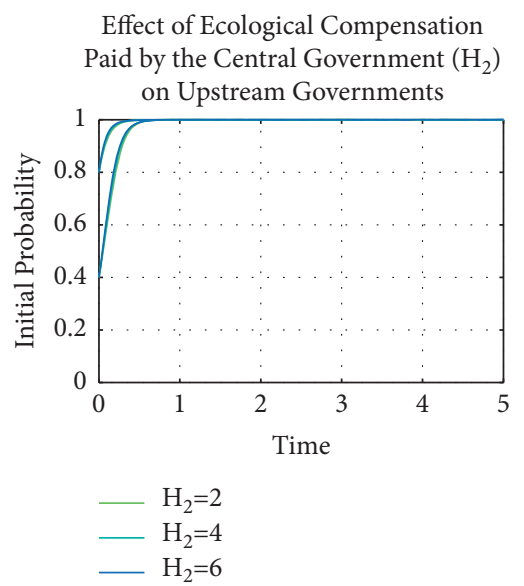

(a)

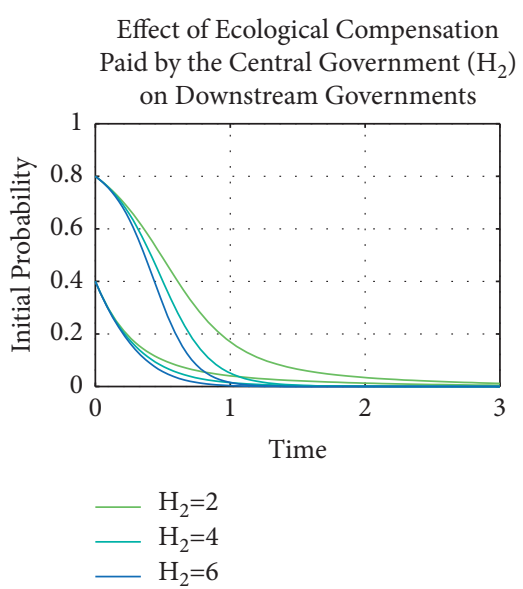

(b)

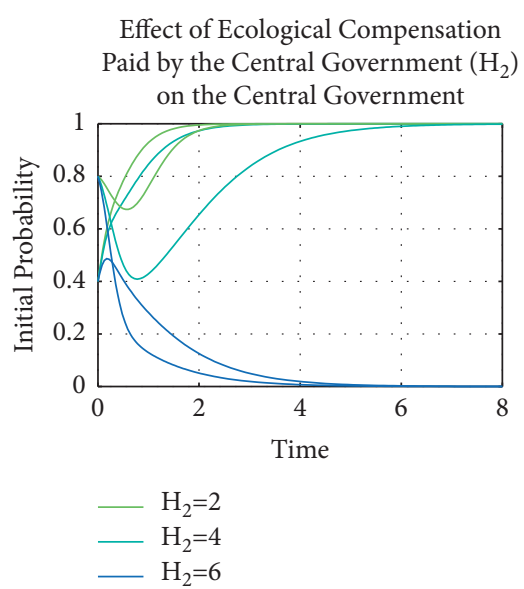

(c)

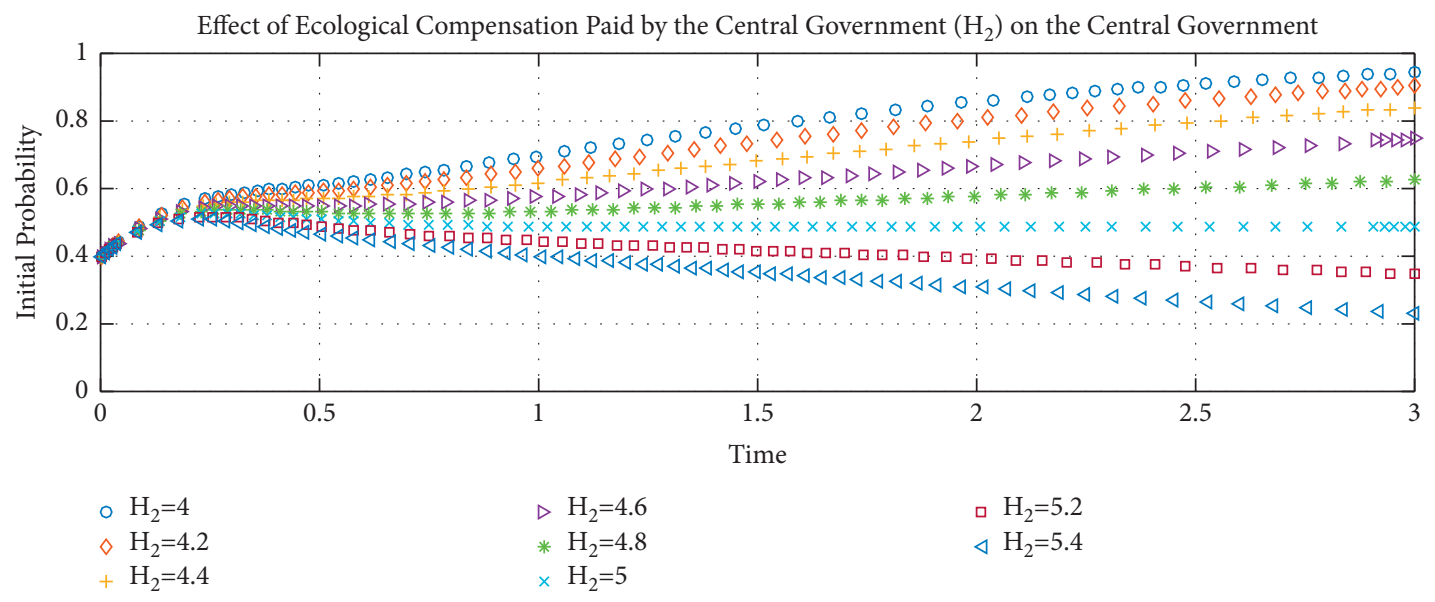

(d)

Figure 7: The effect of the ecological compensation paid by the central government $\left(\mathrm{H}_{2}\right)$ on each player. (a) Effect of the ecological compensation paid by the central government $\left(\mathrm{H}_{2}\right)$ on upstream governments. (b) Effect of the ecological compensation paid by the central government $\left(\mathrm{H}_{2}\right)$ on downstream governments. (c) Effect of the ecological compensation paid by the central government $\left(H_{2}\right)$ on the central government. (d) Effect of the ecological compensation paid by the central government $\left(H_{2}\right)$ on the central government.

trend. It can be seen that upstream governments have strong willingness to participate in WEC, downstream governments have weak willingness to participate, and the central government chooses daily supervision. At present, the water resources protection funds of upstream governments include the transfer payment of the central government and the self-raised funds of upstream governments. Due to the slow economic development and weak financing capacity of upstream governments, the water resources protection funds are mainly borne by the central government. This reflects that the vertical compensation is the mainstream of WEC in China. At this stage, the central government hopes to build horizontal compensation between upstream and downstream governments to supplement vertical compensation, but, from the simulation results, the downstream governments are the key to establish horizontal compensation, and their willingness to participate is not high. Therefore, downstream governments need to fully understand the contribution of upstream governments protecting water resources and improve their willingness to participate in WEC, which will change the current situation of the lack of horizontal compensation.

5.2. Environmental Protection Cost. The establishment and implementation of WEC need the cooperation of governments at all levels, and upstream governments need to invest much direct cost and opportunity cost in protecting water environment. Therefore, this cost is the key factor to WEC. According to the analysis in Section 4.2, the higher the environmental protection cost is, the longer upstream governments take to reach the stable state. Downstream governments are hardly affected. In the low probability group, the central government reaches a stable state faster with the increase of environmental protection cost. The reasons for the above changes are as follows: first, when protecting the water environment, upstream governments not only have to pay a lot of costs for the construction of environmental protection infrastructure but also need to 
implement other measures to maintain the protection effect of water environment, such as limiting the expansion of polluting enterprises and changing the planting structure of local agriculture. Therefore, the higher the cost paid by upstream governments is, the more difficult it is to implement sustainable water environmental protection. Second, due to the continuous increase of environmental costs, upstream governments have the motivation to choose not to protect water environment. In order to ensure the health of water environment in the basin, the central government has to request upstream governments to protect water environment by daily supervision and paying certain compensation. Therefore, effectively reducing the environmental protection cost of upstream governments is the key to promote the sustainable protection of water resources. At present, the Chinese government is reducing the cost of water environmental protection through the following ways: (1) Introduce new green technologies to help upstream governments improve the efficiency of sewage treatment. For example, the central government selects sewage treatment companies with technology and experience through investment to assist upstream governments in building sewage treatment plants. (2) Establish enclaves in the downstream areas and relocate high polluting enterprises in the upstream areas to enclaves and give them corresponding tax relief. On the one hand, it can ensure the normal operation of these polluting enterprises, and, on the other hand, it can reduce the amount of local sewage.

5.3. Fine. The central government's fine to upstream and downstream governments is one of the environmental regulation ways to promote them participating WEC. According to the simulation results in Section 4.3, the fines imposed on upstream governments have no impact on players, while the fines imposed on downstream governments have a great impact on the downstream governments and the central government. When the fine increases to a certain degree, the decision-makings of downstream governments and the central government change periodically. The reasons for the above phenomena are as follows: firstly, the fine will increase the additional cost of downstream governments and increase the income of the central government. Therefore, the decision-making changes between downstream governments and the central government have strong relevance. Secondly, when upstream governments choose to protect water environment, downstream governments try to "free ride" without paying compensation to upstream governments, because it can not only obtain highquality water resources but also pay no price. However, to ensure the continuous protection of water environment by upstream governments, the central government will adopt daily supervision to urge downstream governments to pay certain compensation fee to upstream governments. At this time, in order to deal with daily supervision of the central government, downstream governments will have the tendency to pay compensation. Therefore, the downstream governments will weigh the impact of "free riding" and "daily supervision," so their decision-making curve fluctuates periodically. Finally, the central government will make corresponding adjustments to the strategic changes of downstream governments and finally form periodic changes. However, the central government is more sensitive to the fine of downstream governments, because when $F_{2}$ increases to 9, the central government's strategy curve changes periodically, which can be seen from Figure 5(f). According to the above analysis, the fine of the central government is indispensable for the establishment of WEC mechanism. If downstream governments are sensitive to fine, they can choose compensation by establishing a strict punishment mechanism. However, at present, there is no legislation on ecological compensation in China, so the horizontal compensation between upstream and downstream governments is mainly established through consultation, while the central government only guides. This makes it impossible to punish downstream governments for their no compensation. On September 12, 2021, General Office of the State Council of the PRC issued the opinions on deepening the reform of ecological protection compensation system, which clearly emphasized the use of legal means to regulate ecological protection compensation. Therefore, WEC law will be conducive to the establishment of punishment mechanism, which will promote downstream governments to participate in the construction of WEC.

5.4. Ecological Compensation Fee. Ecological compensation fee is the core to ensure the long-term implementation of WEC. Due to the implementation of WEC, both the downstream governments and the central government will benefit, so how to determine the proportion of compensation funds is the key problem.

According to the simulation results in Sections 4.4 and 4.5 , the compensation paid has little impact on upstream governments but has a greater impact on downstream governments and the central government. First, when compensation fee increases, upstream governments are almost unaffected, which is different from common sense because compensation fee is an additional benefit to upstream governments; when it increases, upstream governments should reach a stable state faster, but this is not reflected in the simulation. This shows that upstream governments need to pay huge costs for protecting water environment, which cannot be compensated by compensation fee. However, due to the policy pressure of the central government, upstream governments have to protect water environment. Therefore, upstream governments are not sensitive to limited compensation fee. Second, compensation fee is an additional expenditure for downstream governments. When compensation fee increases, downstream governments will choose not to compensate, which is the same as the simulation results. Finally, when compensation fee paid by downstream governments $\left(H_{1}\right)$ increases, the central government will reach a stable state faster (Figure 6(c)), which is also different from common sense, because if downstream governments pay compensation fee in time, this can form a virtuous cycle of protecting water resources between upstream and downstream areas, so the 
central government no longer needs daily supervision. However, in the practice of WEC, downstream governments believe that using high-quality water resources is their own right, so they are unwilling to pay compensation fee and continue to choose no-compensation strategy (Figure 6(b)). Then, the central government can only continue to adopt daily supervision to request upstream governments protecting water environment. In addition, when compensation paid by the central government $\left(\mathrm{H}_{2}\right)$ increases from 2 to 4 , the time to reach stable state 1 will be extended. When $\mathrm{H}_{2}$ further increases to 6 , the central government will change from daily supervision to random inspection. This shows that the central government has an upper limit on compensation fee (Figure $7(\mathrm{~d})$ ). Once the compensation fee exceeds the upper limit, the central government will change the strategy. This is consistent with the reality of WEC. At present, the compensation fee paid by the central government is the main source of funds to maintain WEC, which will bring huge financial pressure to itself. Therefore, the central government is also stepping up its research on how to promote the spontaneous construction of ecological compensation mechanism upstream and downstream of the basin, so as to free it from the huge pressure of compensation fee. At present, the Chinese government has carried out horizontal compensation pilot projects in Xin'an River, Chishui River, and other river basins and has gained a lot of practical experience. In addition, it has successively issued guidance on supporting the establishment of horizontal compensation in large river basins such as Yangtze River and Yellow River. Attracting social capital (such as enterprises and the public) to join horizontal compensation is an effective way to increase compensation funds. Improving the trading of water rights and emission rights between upstream and downstream areas is also an important way to effectively promote horizontal compensation.

\section{Conclusion and Suggestion}

6.1. Conclusion. This paper takes upstream governments, downstream governments, and the central government as the research object and analyzes the changes in the decisionmaking process and key influencing factors. This is of great significance to the rational design and implementation of WEC. Our results show that the initial probability significantly affects the decision-making behavior of each player.
Daily supervision of the central government and the cost of water environmental protection play an important role in the establishment of WEC. The fine imposed on the downstream governments will lead to periodic changes in the decision-making of themselves and the central government. There is a critical value for the ecological compensation paid by the central government, which means that reasonably determining the matching relationship between vertical compensation and horizontal compensation can effectively promote the establishment and long-term implementation of WEC. Although this paper has obtained some interesting results, there are still the following limitations: (1) this paper does not include polluting enterprises and the public into the analysis framework; (2) this paper uses simulation technology to study the decision-making process of each subject in WEC but does not introduce actual cases for comparative analysis. In the future, we will use multiagent simulation to include stakeholders such as polluting enterprises and residents in the research framework. Meanwhile, we will obtain the data of actual WEC case through questionnaire survey combined with econometrics and statistical analysis to further verify the theoretical model and conclusions in this paper.

6.2. Suggestion. According to this paper, the following suggestions are put forward: (1) at this stage, the central government should continue to implement daily supervision to ensure the implementation of WEC; (2) improving the initial willingness of governments at all levels to participate in WEC significantly improves its success rate; (3) upstream governments should study new methods and paths to reduce the cost of protecting water environment; (4) the central government should strengthen the supervision and fine on downstream governments; (5) the central government should build a new scheme to promote upstream and downstream governments to spontaneously establish a horizontal compensation mechanism. The implementation of the above suggestions will effectively promote the establishment and implementation of WEC.

\section{Appendix}

The Jacobian matrices of eight equilibrium points are as follows: 


$$
\begin{aligned}
& J_{1}=\left[\begin{array}{ccc}
V_{1}-C_{1} & 0 & 0 \\
0 & -H_{1} & 0 \\
0 & 0 & F_{1}-C_{2}+F_{2}
\end{array}\right], \\
& J_{2}=\left[\begin{array}{ccc}
C_{1}-V_{1} & 0 & 0 \\
0 & -H_{1} & 0 \\
0 & 0 & F_{2}-C_{2}-H_{2}
\end{array}\right] \text {, } \\
& J_{3}=\left[\begin{array}{ccc}
V_{1}-C_{1} & 0 & 0 \\
0 & H_{1} & 0 \\
0 & 0 & F_{1}-C_{2}
\end{array}\right] \text {, } \\
& J_{4}=\left[\begin{array}{ccc}
F_{1}-C_{1}+H_{2}+V_{1} & 0 & 0 \\
0 & F_{2}-H_{1} & 0 \\
0 & 0 & C_{2}-F_{1}-F_{2}
\end{array}\right] \text {, } \\
& J_{5}=\left[\begin{array}{ccc}
C_{1}-V_{1} & 0 & 0 \\
0 & H_{1} & 0 \\
0 & 0 & -C_{2}-H_{2}
\end{array}\right] \text {, } \\
& J_{6}=\left[\begin{array}{ccc}
C_{1}-F_{1}-H_{2}-V_{1} & 0 & 0 \\
0 & F_{2}-H_{1} & 0 \\
0 & 0 & C_{2}-F_{2}+H_{2}
\end{array}\right] \text {, } \\
& J_{7}=\left[\begin{array}{ccc}
F_{1}-C_{1}+H_{2}+V_{1} & 0 & 0 \\
0 & -F_{2}+H_{1} & 0 \\
0 & 0 & C_{2}-F_{1}
\end{array}\right] \text {, } \\
& J_{8}=\left[\begin{array}{ccc}
C_{1}-F_{1}-H_{2}-V_{1} & 0 & 0 \\
0 & -F_{2}+H_{1} & 0 \\
0 & 0 & C_{2}+H_{2}
\end{array}\right] \text {. }
\end{aligned}
$$

\section{Data Availability}

All simulation data used in this paper are listed in the manuscript.

\section{Conflicts of Interest}

The authors declare that there are no conflicts of interest.

\section{Acknowledgments}

This work was funded by the Water Conservancy Science and Technology Projects in Jiangsu Province (no. 2018034).

\section{References}

[1] N. Li, G. Tang, P. Zhao, Y. Hong, Y. Gou, and K. Yang, "Statistical assessment and hydrological utility of the latest multi-satellite precipitation analysis IMERG in Ganjiang river basin," Atmospheric Research, vol. 183, pp. 212-223, 2017.

[2] M. Chen, Y. Lu, L. Ling, Y. Wan, Z. Luo, and H. Huang, "Drivers of changes in ecosystem service values in Ganjiang upstream watershed," Land Use Policy, vol. 47, pp. 247-252, 2015.
[3] S. Jichuan and W. Michael, "Incentive coordination for transboundary water pollution control: the case of the middle route of China's South-North water transfer project - sciencedirect," Journal of Hydrology, vol. 598, Article ID 125705, 2020.

[4] J. Osán, S. Török, B. Alföldy, and G. Falkenberg, "Characterization of anthropogenic sediment particles after a transboundary water pollution of river Tisza using synchrotron radiation," Spectrochimica Acta Part B: Atomic Spectroscopy, vol. 59, no. 5, pp. 701-708, 2004.

[5] X. Gao, J. Shen, W. He et al., "Multilevel governments' decision-making process and its influencing factors in watershed ecological compensation," Sustainability, vol. 11, pp. 1-28, 2019.

[6] H. Li, J. Lu, and P. Research, "Can regional integration control transboundary water pollution? A test from the Yangtze river economic belt," Environmental Science and Pollution Research, vol. 27, no. 22, pp. 28288-28305, 2020.

[7] Q. Wang, Q. Fu, Z. Shi, and X. Yang, "Transboundary water pollution and promotion incentives in China," Journal of Cleaner Production, vol. 261, Article ID 121120, 2020.

[8] J. Lu and P. Research, "Turnover of environmental protection officials and transboundary water pollution," Environmental Science and Pollution Research, vol. 28, pp. 1-17, 2020.

[9] L. Zhao, C. Li, R. Huang et al., "Harmonizing model with transfer tax on water pollution across regional boundaries in a China's lake basin," European Journal of Operational Research, vol. 225, no. 2, pp. 377-382, 2013.

[10] J. Shen, X. Gao, W. He et al., "Prospect theory in an evolutionary game: construction of watershed ecological compensation system in Taihu lake basin," Journal of Cleaner Production, vol. 291, Article ID 125929, 2021.

[11] X. Guan, W. Liu, M. Chen, J. Ecolind, T. Control, and E. C. Standard, "Study on the ecological compensation standard for river basin water environment based on total pollutants control," Ecological Indicators, vol. 69, pp. 446-452, 2016.

[12] N. Grima, S. J. Singh, B. Smetschka, and L. Ringhofer, "Payment for ecosystem services (PES) in Latin America: analysing the performance of 40 case studies," Ecosystem Services, vol. 17, pp. 24-32, 2016.

[13] X. Kai, K. Fanbin, Z. Ning, N. Lei, and C. Sun, "Analysis of the factors influencing willingness to pay and payout level for ecological environment improvement of the ganjiang river basin," Sustainability, vol. 10, p. 2149, 2018.

[14] X. Pan, L. Xu, Z. Yang, and Y. Bing, "Payments for ecosystem services in China: policy, practice, and progress," Journal of Cleaner Production, vol. 21, pp. 109-119, 2017.

[15] Mo.Fo.t.Ps.Ro China, "Guiding opinions on establishing and perfecting long-term mechanism of ecological compensation and protection in the Yangtze river economic zone," Availabe online: http://ln.mof.gov.cn/lanmudaohang/zhengcefagui/ 201802/t20180228_2822651.html (accessed on October, 6), 2018.

[16] Z. Zhang, J. Gao, X. Fan, Y. Lan, and M. Zhao, "Response of ecosystem services to socioeconomic development in the Yangtze river basin, China," Ecological Indicators, vol. 72, pp. 481-493, 2017.

[17] China, "Mo.Fo.t.Ps.Ro. guiding opinions on establishing and perfecting the long-term mechanism of ecological compensation and protection in the Yangtze river economic zone," Availabe online: http://www.gov.cn/xinwen/2018-02/24/content_5268509.htm (accessed on October 6), 2018.

[18] X. Gao, J. Shen, W. He et al., "An evolutionary game analysis of governments' decision-making behaviors and factors 
influencing watershed ecological compensation in China," Journal of Environmental Management, vol. 251, Article ID 109592, 2019.

[19] D. Feng, W. Wu, L. Liang, L. Li, and G. Zhao, "Payments for watershed ecosystem services: mechanism, progress and challenges," Ecosystem Health and Sustainability, vol. 4, no. 1, pp. 13-28, 2018.

[20] Y. J. Wang, G. X. Bing, Q. L. Xiao, Y. L. Hong, and Y. Jin, "Ecological compensation standards and compensation methods of public welfare forest protected area," Chinese Journal of Applied Ecology, vol. 27, pp. 1893-1900, 2016.

[21] W. Sheng, L. Zhen, G. Xie, and Y. Xiao, "Determining ecocompensation standards based on the ecosystem services value of the mountain ecological forests in Beijing, China," Ecosystem Services, vol. 26, pp. 422-430, 2017.

[22] X. Gao, J. Shen, W. He et al., "Changes in ecosystem services value and establishment of watershed ecological compensation standards," International Journal of Environmental Research and Public Health, vol. 16, no. 16, p. 2951, 2019.

[23] B. Yu, L. Xu, and S. E. Reviews, "Review of ecological compensation in hydropower development," Renewable and Sustainable Energy Reviews, vol. 55, pp. 729-738, 2016.

[24] K. Johst, M. Drechsler, and F. Wätzold, "An ecologicaleconomic modelling procedure to design compensation payments for the efficient spatio-temporal allocation of species protection measures," Ecological Economics, vol. 41, no. 1, pp. 37-49, 2002.

[25] Y. M. Jie, G. E. Yan-Xiang, X. U. J. O. R. Guang-Li, and M. Science, "Cooperation evolution of ecological compensation between waterhead region and downstream based on evolutionary game," Operations Research and Management Science, vol. 21, pp. 137-143, 2012.

[26] H. Xie, W. Wang, and X. Zhang, "Evolutionary game and simulation of management strategies of fallow cultivated land: a case study in Hunan province, China," Land Use Policy, vol. 71, pp. 86-97, 2018.

[27] R. Moreno-Sanchez, J. H. Maldonado, S. Wunder, and C. Borda-Almanza, "Heterogeneous users and willingness to pay in an ongoing payment for watershed protection initiative in the Colombian Andes," Ecological Economics, vol. 75, pp. 126-134, 2012.

[28] G. Van Hecken, J. Bastiaensen, and W. F. Vásquez, "The viability of local payments for watershed services: e," Ecological Economics, vol. 74, pp. 169-176, 2012.

[29] X. Zhang, X. Gao, and I. Amp, "Research on intergovernmental watershed ecological compensation mechanism based on game theory," Value Engineering, vol. 36, pp. 110-112, 2018.

[30] Y. Zhao and S. Dong, "Research on ecological compensation in the Yellow River basin based on the perspective of game theory," E3S Web of Conferences, vol. 275, Article ID 02002, 2021.

[31] H. U. Dongbin, H. Liu, X. Chen, and Y. Chen, "Research on the ecological compensation standard of the basin pollution control project based on evolutionary game theory and by taking Xiangjiang river as a case," Frontiers of Engineering Management, vol. 6, pp. 575-583, 2019.

[32] D. Friedman, "On economic applications of evolutionary game theory," Journal of Evolutionary Economics, vol. 8, no. 1, pp. 15-43, 1998.

[33] K. Ritzberger and J. W. Weibull, "Evolutionary selection in normal-form games," Econometrica, vol. 63, no. 6, pp. 1371-1399, 1995.
[34] C. Schmidt, "Are evolutionary games another way of thinking about game theory?" Journal of Evolutionary Economics, vol. 14, no. 2, pp. 249-262, 2004.

[35] R. Cressman and J. Apaloo, Evolutionary Game Theory, MIT Press, Cambridge, MA, USA, 2016.

[36] A. J. Robson, "Individual strategy and social structure: an evolutionary theory of institutions," The Canadian Journal of Economics/Revue Canadienne D'economique, vol. 3, pp. 329-331, 1999.

[37] H. Zhang, Y. Ge, and Y. Jie, "Analysis of replicated dynamics and evolutionary stability strategies of watershed ecological compensation,” Statistics \& Decisions, vol. 34, pp. 50-53, 2018.

[38] Bomze, M. Immanuel, Weibull, and W. Jorgen, "Does neutral stability imply Lyapunov stability?" Games and Economic Behavior, vol. 11, pp. 173-192, 1995.

[39] S. R. Vadali and E. S. Kim, "Feedback control of tethered satellites using Lyapunov stability theory," Journal of Guidance, Control, and Dynamics, vol. 14, pp. 729-735, 2015. 